\title{
Psoriasis y diabetes mellitus en la consulta dermatológica
}

\author{
Lucero Barreda-Zaleta', Diego Olin Pérez-Rojas², Claudia Jessica Espinoza-Hernández³, \\ Ana Laura Ramírez-Terán ${ }^{4}$ y María Elisa Vega-Memije 3 \\ ${ }^{1}$ Escuela Nacional de Medicina y Homeopatía, Instituto Politécnico Nacional; ${ }^{2}$ Facultad de Medicina, Universidad Nacional Autónoma de México; \\ ${ }^{3}$ Departamento de Dermatopatología; ${ }^{4}$ Departamento de Dermatología. Hospital General Dr. Manuel Gea González. Ciudad de México, México
}

\section{Sr. Editor:}

La psoriasis es una enfermedad inflamatoria de la piel, de evolución crónica, que afecta al 2-3\% de la población en todo el mundo y en México representa el $2 \%$ de la consulta dermatológica ${ }^{1,2}$. Se caracteriza por la presencia de placas eritematoescamosas bien delimitadas que afectan superficies extensoras. Con menos frecuencia se observa compromiso ungueal y articular. Es más común en los caucásicos y afecta por igual a hombres y mujeres'. Tiene una edad promedio de presentación entre la segunda y la cuarta décadas de la vida ${ }^{3}$.

La etiología de la psoriasis es desconocida; se han descrito factores genéticos, ambientales, inmunitarios, infecciosos y psicosomáticos que influyen en la enfermedad ${ }^{4}$. Se ha encontrado una asociación estrecha entre esta dermatosis, el riesgo cardiovascular y los componentes del síndrome metabólico, en especial con la diabetes mellitus (DM) $)^{5-7}$.

La inflamación es el principal factor que vincula la psoriasis con los demás componentes del síndrome metabólico, y existen múltiples teorías que son de utilidad para explicar esta asociación. La presencia crónica de mediadores inflamatorios sistémicos altera el metabolismo del tejido graso, produciendo secundariamente una inhibición de la secreción de insulina. Lo anterior conduce a un estado de hiperglucemia, resistencia a la insulina y finalmente $\mathrm{DM}^{8,9}$.

En nuestro país, que tiene como problema de salud pública a la DM, se han realizado pocos estudios sobre la prevalencia y la asociación de estas dos enfermedades en población mexicana, por lo que consideramos relevante describir las características epidemiológicas de nuestra población con psoriasis.

Por ello, comunicamos la coexistencia de psoriasis y DM en pacientes registrados en el Hospital General Dr. Manuel Gea González. Se revisaron pacientes de ambos sexos, de cualquier edad, con diagnóstico de esta dermatosis, que acudieron a consulta externa del servicio de dermatología en el periodo de 2010 a 2016.

Se obtuvieron los siguientes resultados: de 206 pacientes con diagnóstico de psoriasis, el 53.9\% $(n=111)$ eran de sexo femenino y el $46.1 \%(n=95)$ masculino. El $51.9 \%(n=107)$ de los pacientes pertenecía al grupo de edad de 41-60 años. La edad media fue de 50 años. El $28.2 \%(n=58)$ de los pacientes estudiados presentaba comorbilidad con DM ya diagnosticada, y de estos, el $62 \%(n=36)$ eran mujeres y el $38 \%$ ( $n=22$ ) hombres.

En un estudio realizado en población mexicana con 114 pacientes se evaluó la coexistencia de estas dos enfermedades, observándose un $26.9 \%{ }^{10}$, lo que se correlaciona con los resultados obtenidos en este trabajo, del $28.2 \%$. También observamos predominio de esta asociación entre psoriasis y DM en las mujeres, como se ha reportado anteriormente en población mexicana ${ }^{11}$. En este último estudio se encontró que los pacientes con psoriasis grave presentan valores de glucosa más elevados ${ }^{11}$.

Con estos hallazgos, podemos informar que la psoriasis puede cursar con DM diagnosticada en un porcentaje considerable, y faltaría estudiar en qué porcentaje del resto de los pacientes no se ha

\section{Correspondencia:}

Gac Med Mex. 2017;153:524-525

Contents available at PubMed www.gacetamedicademexico.com 
diagnosticado la enfermedad. La asociación entre estas dos enfermedades afecta más a las mujeres de la población estudiada, por lo que es sumamente importante su evaluación médica desde el primer nivel de atención y realizar más estudios al respecto con un enfoque multidisciplinario entre dermatólogos, médicos internistas, endocrinólogos y cardiólogos.

\section{Bibliografía}

1. Arenas R. Dermatología. Atlas, diagnóstico y tratamiento. $5^{\mathrm{a}}$ ed. México: McGraw Hill; 2013. p. 609-19.

2. Tavizón-Ramos OE, Aguirre-González JD, Peralta-Pedrero ML, et al. Tratamiento farmacológico para pacientes adultos con psoriasis en placas. México: Secretaría de Salud; 2013. Disponible en: http://www.cenetec.salud.gob.mx
3. Ponce-Rodríguez M, Mendoza R. Características clínico-epidemiológicas de pacientes con psoriasis en un hospital nacional. Dermatol Peru. 2012;22:144-50.

4. Krueger G, Ellis CN. Psoriasis - recent advances in understanding its pathogenesis and treatment. J Am Acad Dermatol. 2005;53:94-100.

5. Armstrong AW, Harskamp CT, Armstrong EJ. Psoriasis and metabolic syndrome: a systematic review and meta-analysis of observational studies. J Am Acad Dermatol. 2013:68:654-62.

6. Cheng J, Kuai D, Zhang L, et al. Psoriasis increased the risk of diabetes: a meta-analysis. Arch Dermatol Res. 2012;304:119-25.

7. Brauchli YB, Jick SS, Meier CR. Psoriasis and the risk of incident diabetes mellitus: a population-based study. $\mathrm{Br} J$ Dermatol. 2008;159:1331-7.

8. Zhao YF, Feng DD, Chen C. Contribution of adipocyte-derived factors to beta-cell dysfunction in diabetes. Int J Biochem Cell Biol. 2006;38:804-19.

9. Trevisan M, Liu J, Bahsas FB, et al. Syndrome X and mortality: a population-based study. Am J Epidemiol. 1998;148:958-66.

10. Chanussot $C$, Arenas R. Psoriasis. Estudio descriptivo y comorbilidades en 114 pacientes. Dermatología CMQ. 2015;13:20-3

11. Espinoza-Hernandez CJ, Lacy-Niebla RM, Soto-López ME, et al. Prevalencia del síndrome metabólico (SM) en pacientes con psoriasis. Gac Med Mex. 2014;150:311-6. 